\title{
Acetate turnover and methanogenic pathways in Amazonian lake sediments
}

\author{
Ralf Conrad $^{1}$, Melanie Klose ${ }^{1}$, and Alex Enrich-Prast ${ }^{2,3}$ \\ ${ }^{1}$ Max Planck Institute for Terrestrial Microbiology, Karl-von-Frisch-Str. 10, 35043 Marburg, Germany \\ ${ }^{2}$ Department of Thematic Studies - Environmental Change, Linköping University, Linköping, Sweden \\ ${ }^{3}$ Departamento de Botânica, Instituto de Biologia, University Federal do Rio de Janeiro (UFRJ), Rio de Janeiro, Brazil
}

Correspondence: Ralf Conrad (conrad@mpi-marburg.mpg.de)

Received: 11 October 2019 - Discussion started: 23 October 2019

Revised: 27 December 2019 - Accepted: 29 January 2020 - Published: 26 February 2020

\begin{abstract}
Lake sediments in Amazonia are a significant source of $\mathrm{CH}_{4}$, a potential greenhouse gas. Previous studies of sediments using ${ }^{13} \mathrm{C}$ analysis found that the contribution of hydrogenotrophic versus acetoclastic methanogenesis to $\mathrm{CH}_{4}$ production was relatively high. Here, we determined the methanogenic pathway in the same sediments $(n=6)$ by applying ${ }^{14}$ Cbicarbonate or $2-{ }^{14}$ Cacetate and confirmed the high relative contribution (50\%-80\%) of hydrogenotrophic methanogenesis. The respiratory index (RI) of $2-{ }^{14}$ Cacetate, which is ${ }^{14} \mathrm{CO}_{2}$ relative to ${ }^{14} \mathrm{CH}_{4}+{ }^{14} \mathrm{CO}_{2}$, divided the sediments into two categories, i.e., those with an $\mathrm{RI}<0.2$ consistent with the operation of acetoclastic methanogenesis and those with an RI $>0.4$ showing that a large percentage of the acetate-methyl was oxidized to $\mathrm{CO}_{2}$ rather than reduced to $\mathrm{CH}_{4}$. Hence, part of the acetate was probably converted to $\mathrm{CO}_{2}$ plus $\mathrm{H}_{2}$ via syntrophic oxidation, thus enhancing hydrogenotrophic methanogenesis. This happened despite the presence of potentially acetoclastic Methanosaetaceae in all the sediments. Alternatively, acetate may have been oxidized with a constituent of the sediment organic matter (humic acid) serving as oxidant. Indeed, apparent acetate turnover rates were larger than $\mathrm{CH}_{4}$ production rates except in those sediments with a $R<0.2$. Our study demonstrates that $\mathrm{CH}_{4}$ production in Amazonian lake sediments was not simply caused by a combination of hydrogenotrophic and acetoclastic methanogenesis but probably involved additional acetate turnover.
\end{abstract}

\section{Introduction}

Acetate is an important intermediate in the anoxic degradation of organic matter and is produced by fermentation processes and chemolithotrophic homoacetogenesis. The contribution of these two processes to acetate production is difficult to determine but seems to be quite different for different environments (Fu et al., 2018; Hädrich et al., 2012; Heuer et al., 2010; Lokshina et al., 2019; Ye et al., 2014). The degradation of acetate requires a suitable oxidant such as oxygen, nitrate, ferric iron or sulfate. If such oxidants are not or no longer available, such as in many freshwater environments (e.g., paddy fields, lake sediments, peat), acetate sometimes accumulates until suitable electron acceptors become available again. Temporal accumulation and subsequent oxidative consumption has, for example, been observed in peatlands during increase and decrease, respectively, of the water table (Duddleston et al., 2002). However, it is generally assumed that acetate degradation in the absence of inorganic electron acceptors is accomplished by acetoclastic methanogenesis (Zinder, 1993). If acetoclastic methanogenesis is operative, the methyl group of the acetate is converted to $\mathrm{CH}_{4}$.

If methanogenesis is the exclusive final step in the anaerobic degradation of organic matter, polysaccharides (one of the most important compounds from primary production) will be dismutated to equal amounts of $\mathrm{CH}_{4}$ and $\mathrm{CO}_{2}$. Furthermore, acetate usually accounts for more than two-thirds of total methane production, especially if polysaccharides are the predominant degradable organic matter (Conrad, 1999). However, $\mathrm{CO}_{2}$ has often been found to be the main product in many anoxic environments despite the absence of inorganic electron acceptors $\left(\mathrm{O}_{2}\right.$, nitrate, ferric iron, sulfate $)$ 
(Keller et al., 2009; Yavitt and Seidmann-Zager, 2006). Such results have been explained by the assumption that organic substances (e.g., humic acids) may also serve as electron acceptors (Gao et al., 2019; Keller et al., 2009; Klüpfel et al., 2014). Organic electron acceptors also allow the oxidation of acetate (Coates et al., 1998; Lovley et al., 1996). The role of organic electron acceptors during anaerobic degradation of organic matter is potentially important but still not well known (Corbett et al., 2013)

There are also many reports that methane production in lake sediments is dominated by hydrogenotrophic rather than acetoclastic methanogenesis (Conrad, 1999; Conrad et al., 2011; Ji et al., 2016). Such observations were explained (1) by incomplete degradation of organic matter producing predominantly $\mathrm{H}_{2}$ and $\mathrm{CO}_{2}$ without concomitant acetate production (Conrad et al., 2010; Hodgkins et al., 2014; Liu et al., 2017), (2) by acetate oxidation coupled to the reduction of organic substances (see above) or (3) by syntrophic acetate oxidation coupled with hydrogenotrophic methanogenesis (Lee and Zinder, 1988; Vavilin et al., 2017). If acetate oxidation is operative, the methyl group of the acetate is converted to $\mathrm{CO}_{2}$. However, if acetate oxidation is syntrophic, it does not require a chemical compound (other than $\mathrm{H}^{+}$) as electron acceptors, since it is the hydrogenotrophic methanogenesis that eventually accepts the electrons released during acetate oxidation.

Syntrophic acetate oxidation can replace acetoclastic methanogenesis and thus has been found when acetoclastic methanogenic archaea were not present in the microbial community of lake sediment (Nüsslein et al., 2001). This may also happen in other anoxic environments when conditions are not suitable for acetoclastic methanogens, e.g., at elevated temperatures (Conrad et al., 2009; Liu and Conrad, 2010; Liu et al., 2018) or in the presence of high concentrations of ammonium (Müller et al., 2016; Schnürer et al., 1999; Zhang et al., 2014) or phosphate (Conrad et al., 2000). However, syntrophic acetate oxidation has also been found in lake sediments that contained populations of putatively acetoclastic methanogens (Vavilin et al., 2017). It is presently unknown under which conditions syntrophic acetate oxidizers can successfully compete with acetoclastic methanogens and co-occur with acetate oxidation that is coupled to the reduction of organic substances.

As a further step in understanding the ecology of acetate oxidizers (syntrophic or non-syntrophic ones) versus acetoclastic methanogens, we attempted to document their coexistence by studying lake sediments, which had been reported as containing 16S rRNA genes of putatively acetoclastic Methanosaetaceae (Methanotrichaceae, Oren, 2014) (Ji et al., 2016). We used these sediments and measured the fractions of hydrogenotrophic methanogenesis and of the methyl group of acetate being oxidized to $\mathrm{CO}_{2}$ rather than reduced to $\mathrm{CH}_{4}$ and compared the turnover of acetate to the production rate of $\mathrm{CH}_{4}$.

\section{Materials and methods}

The sediment samples were obtained from floodplain lakes in the Amazon region and have already been used for a study on structure and function of methanogenic microbial communities (Ji et al., 2016). In particular, these sediment have been assayed for the percentage of hydrogenotrophic methanogenesis and for the percentage contribution of putatively acetoclastic methanogens to the total archaeal community (Ji et al., 2016). Here, we used six of these sediments for incubation experiments with radioactive tracers. These are the same sediment samples as those listed in our previous publication (Ji et al., 2016). The identity of the lake sediments and the percentage content of putatively acetoclastic methanogens is summarized in Table 1.The experiments were carried out at the same time as those in our previous publication (Ji et al., 2016) and were basically using the same incubation techniques. However, the experimental approach to determine the fractions of hydrogenotrophic methanogenesis $\left(f_{\mathrm{H}_{2}}\right)$ was different. In our previous experiment, values of $f_{\mathrm{H}_{2}}$ were determined from the $\delta^{13} \mathrm{C}$ of $\mathrm{CH}_{4}$ in the presence $\left(\delta^{13} \mathrm{C}_{\mathrm{CH}_{4}-\mathrm{mc}}\right)$ and absence $\left(\delta^{13} \mathrm{C}_{\mathrm{CH}_{4}}\right)$ of methyl fluoride, an inhibitor of acetoclastic methanogenesis, and from the $\delta^{13} \mathrm{C}$ of the methyl group of acetate $\left(\delta^{13} \mathrm{C}_{\mathrm{ac}-\text { methyl }}\right)$.

$$
\begin{aligned}
f_{\mathrm{H}_{2}}= & \left(\delta^{13} \mathrm{C}_{\mathrm{CH}_{4}}-\delta^{13} \mathrm{C}_{\mathrm{ac}-\text { methyl }}\right) / \\
& \left(\delta^{13} \mathrm{C}_{\mathrm{CH}_{4} \text {-mc }}-\delta^{13} \mathrm{C}_{\text {ac-methyl }}\right)
\end{aligned}
$$

The $\mathrm{CH}_{4}$ production rates and $f_{\mathrm{H}_{2}}$ values from this experiment are shown in Fig. 1 for comparison.

In the present experiment, however, values of $f_{\mathrm{H}_{2}}$ were determined by addition of $\mathrm{NaH}^{14} \mathrm{CO}_{3}$ and measurement of the specific radioactivities in $\mathrm{CH}_{4}$ and $\mathrm{CO}_{2}$. Briefly, about $10-15 \mathrm{~mL}$ of each replicate $(n=3)$ was poured into $27 \mathrm{~mL}$ sterile tubes, flushed with $\mathrm{N}_{2}$, closed with butyl rubber stoppers and incubated at $25^{\circ} \mathrm{C}$. After preincubation for $12 \mathrm{~d}$ (in order to deplete eventually present inorganic oxidants), $0.5 \mathrm{~mL}$ of a solution of carrier-free $\mathrm{NaH}^{14} \mathrm{CO}_{3}$ (about $1 \mu \mathrm{Ci}$; $50 \mathrm{Ci} \mathrm{mol}^{-1}$ ) was added, the tubes were flushed again with $\mathrm{N}_{2}$ and incubation was continued at $25^{\circ} \mathrm{C}$ for about $100 \mathrm{~d}$. Partial pressures of $\mathrm{CH}_{4}$ and $\mathrm{CO}_{2}$, as well as their contents of ${ }^{14} \mathrm{C}$, were measured at different time points after mixing the slurries by heavy manual shaking. The gas partial pressures were measured by gas chromatography with a flame ionization detector ( $\mathrm{Ji}$ et al., 2016), and the radioactivities were analyzed with a radio detector (RAGA) (Conrad et al., 1989). The data were used to calculate the fractions of hydrogenotrophic methanogenesis $\left(f_{\mathrm{H}_{2}}\right)$ from the specific radioactivities of gaseous $\mathrm{CH}_{4}\left(\mathrm{SR}_{\mathrm{CH}_{4}}\right)$ and $\mathrm{CO}_{2}\left(\mathrm{SR}_{\mathrm{CO}_{2}}\right)$ :

$f_{\mathrm{H}_{2}}=\mathrm{SR}_{\mathrm{CH}_{4}} / \mathrm{SR}_{\mathrm{CO}_{2}}$.

For determination of acetate turnover, the same conditions were used, except that preincubation was for $25 \mathrm{~d}, 0.5 \mathrm{~mL}$ 
Table 1. Identity of sediment samples (following Ji et al., 2016) and percentage content of putatively acetoclastic methanogens (Methanosaetaceae) relative to total archaea and concentrations of acetate (mean $\pm \mathrm{SE}$ ).

\begin{tabular}{lllrr}
\hline Lake no. & Name & Type & $\begin{array}{r}\text { Methanosaetaceae } \\
(\%)\end{array}$ & $\begin{array}{r}\text { Acetate } \\
\left(\mathrm{nmol} \mathrm{g}^{-1} \text { dry weight }\right)\end{array}$ \\
\hline P1 & Jua & clear water & $21 \pm 1$ & $93 \pm 5$ \\
P8 & Tapari & clear water & $19 \pm 3$ & $261 \pm 39$ \\
P9 & Verde & clear water & $19 \pm 11$ & $126 \pm 12$ \\
P10 & Jupinda & clear water & $27 \pm 4$ & $110 \pm 6$ \\
A1 & Cataldo & white water & $42 \pm 1$ & $50 \pm 3$ \\
A2 & Grande & white water & $36 \pm 3$ & $35 \pm 1$ \\
\hline
\end{tabular}

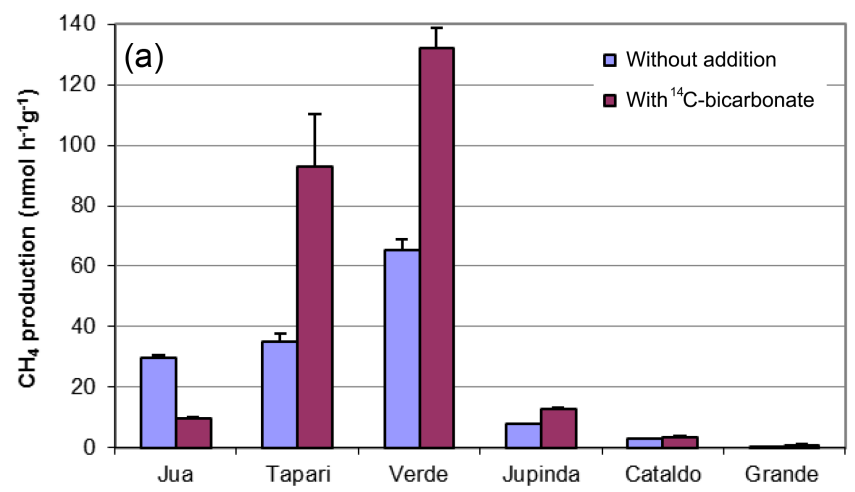

$\mathrm{CH}_{4}$ and $\mathrm{CO}_{2}$ were analyzed again. The data were used to calculate the acetate turnover rate constants $\left(k_{\mathrm{ac}}\right)$ and the respiratory index (RI) values from the radioactivities of gaseous $\mathrm{CH}_{4}$ and $\mathrm{CO}_{2}$, as described by Schütz et al. (1989). The RI is defined as follows:

$\mathrm{RI}={ }^{14} \mathrm{CO}_{2} /\left({ }^{14} \mathrm{CO}_{2}+{ }^{14} \mathrm{CH}_{4}\right)$.

Both ${ }^{14} \mathrm{CH}_{4}$ and ${ }^{14} \mathrm{CO}_{2}$ were measured at the end of the incubation after acidification. The acetate turnover rate constants were determined from the change of ${ }^{14} \mathrm{CH}_{4}$ and ${ }^{14} \mathrm{CO}_{2}$ with incubation time $(t)$ and the maximal values of ${ }^{14} \mathrm{CH}_{4}$ and ${ }^{14} \mathrm{CO}_{2}$ at the end of the incubation before acidification.

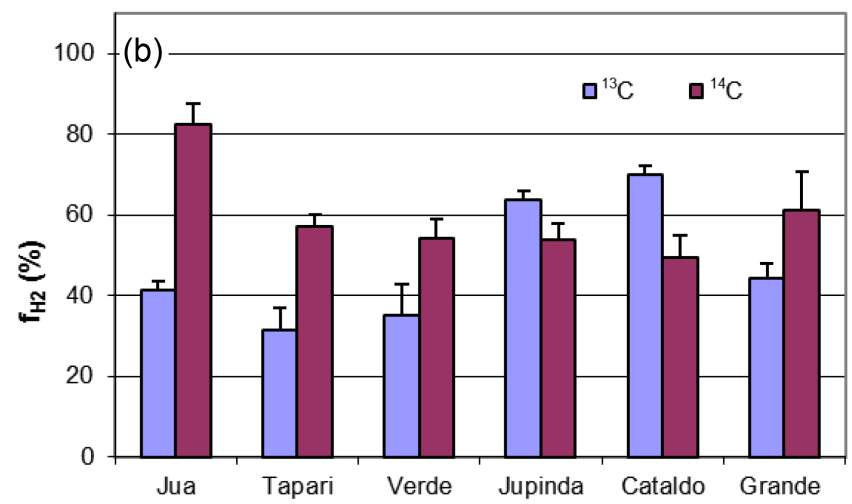

$$
\begin{aligned}
k_{\mathrm{ac}}= & {\left[\operatorname { l n } \left(1-\left({ }^{14} \mathrm{CH}_{4}+{ }^{14} \mathrm{CO}_{2}\right) /\right.\right.} \\
& \left.\left.\left({ }^{14} \mathrm{CH}_{4-\max }+{ }^{14} \mathrm{CO}_{2-\max }\right)\right)\right] / t .
\end{aligned}
$$

The acetate turnover rates $\left(v_{\mathrm{ac}}\right)$ were calculated by the following equation:

$v_{\mathrm{ac}}=k_{\mathrm{ac}} \cdot \mathrm{ac}$.

The acetate concentration (ac) was analyzed in the sediments at the end of the incubation using high-pressure liquid chromatography. The acetate concentrations are summarized in Table 1. The rates of acetate-dependent $\mathrm{CH}_{4}$ production $\left(P_{\mathrm{ac}}\right)$ were calculated from the acetate turnover rates and the RI:

nian lakes: (a) rates of $\mathrm{CH}_{4}$ production and (b) fractions of hydrogenotrophic methanogenesis, both determined in the absence and the presence of radioactive bicarbonate. The data in the absence of radioactive bicarbonate are the same as published in $\mathrm{Ji}$ et al. (2016), when $f_{\mathrm{H}_{2}}$ was determined from values of $\delta^{13} \mathrm{C}$ (mean $\pm \mathrm{SE})$.

of a solution of carrier-free $\mathrm{Na} 2-{ }^{14}$ Cacetate (about $2 \mu \mathrm{Ci}$; $50 \mathrm{Ci} \mathrm{mol}^{-1}$ ), equivalent to about $20 \mathrm{nmol}$ acetate, was added and incubation was continued for about $8 \mathrm{~h}$. During this time, gas samples were repeatedly taken and the radioactivities in $\mathrm{CH}_{4}$ and $\mathrm{CO}_{2}$ were analyzed in a gas chromatograph with a radio detector (RAGA) (Conrad et al., 1989). In the end, the sediment samples were acidified with $1 \mathrm{~mL}$ of $1 \mathrm{M} \mathrm{H}_{2} \mathrm{SO}_{4}$ to liberate $\mathrm{CO}_{2}$ from carbonates, and the radioactivities in

$P_{\mathrm{ac}}=v_{\mathrm{ac}} \cdot(1-\mathrm{RI})$.

\section{Results}

Six different lake sediments from Amazonia were incubated in the presence of $\mathrm{H}^{14} \mathrm{CO}_{3}$. Methane production started without a lag phase, indicating that the inorganic electron acceptors, which were present in the original sediment ( $\mathrm{Ji}$ et al., 2016) had been depleted during the anaerobic preincubation and did not suppress methanogenesis. The $\mathrm{CH}_{4}$ production rates were compared to those obtained in our previous experiments without addition of $\mathrm{H}^{14} \mathrm{CO}_{3}$ (Ji et al., 2016). 
Although the rates of $\mathrm{CH}_{4}$ production were different in the two different incubations, the orders of magnitude were similar for the different lake sediments (Fig. 1a). The incubations in the presence of $\mathrm{H}^{14} \mathrm{CO}_{3}$ were used to follow the specific radioactivities of $\mathrm{CH}_{4}$ (Fig. 2a) and $\mathrm{CO}_{2}$ (Fig. 2b) over the incubation time. The specific radioactivities of $\mathrm{CH}_{4}$ changed only little but were slightly different for the different lake sediments. The specific radioactivities of $\mathrm{CO}_{2}$ decreased with time, as expected due to the production of nonradioactive $\mathrm{CO}_{2}$. Both specific radioactivities were used to calculate the fractions of hydrogenotrophic methanogenesis $\left(f_{\mathrm{H}_{2}}\right)$, which increased with incubation time and eventually reached a plateau. The values of $f_{\mathrm{H}_{2}}$ averaged between 30 and $60 \mathrm{~d}$ of incubation are summarized in Fig. 1b. Only the incubations of sediment "Grande" did not reach a plateau but still increased after $260 \mathrm{~d}$ of incubation due to the continuously decreasing specific radioactivities of $\mathrm{CO}_{2}$ (data not shown). Averaging these values over the four data points between 160 and $260 \mathrm{~d}$ resulted in $f_{\mathrm{H}_{2}}$ of about $60 \%$ (Fig. 1b). The thus-determined values of $f_{\mathrm{H}_{2}}$ were comparable to those determined in the absence of $\mathrm{H}^{14} \mathrm{CO}_{3}$ using values of $\delta^{13} \mathrm{C}$, which have already been published (Ji et al., 2016) (Fig. 1b).

The same sediments were used to determine the turnover of $2-{ }^{14}$ Cacetate by measuring the increase in radioactive $\mathrm{CH}_{4}$ (Fig. 3a) and $\mathrm{CO}_{2}$ (Fig. 3b). These data were used to determine the rate constants of acetate turnover (Fig. 3c), which ranged between 0.02 and $1.7 \mathrm{~h}^{-1}$. The respiratory indices (RI) were generally larger than 0.2 except those of the sediments Tapari and Verde, which were smaller than 0.2 (Fig. 4b). The RI values and the acetate turnover rate constants were used to calculate the rates of $\mathrm{CH}_{4}$ production from acetate in comparison to the rates of total $\mathrm{CH}_{4}$ production (Fig. 4a). Interestingly, acetate-dependent $\mathrm{CH}_{4}$ production was always larger than total $\mathrm{CH}_{4}$ production, except in those sediments exhibiting an $\mathrm{RI}<0.2$.

\section{Discussion}

The RI value quantifies the fraction of the methyl group of acetate that is oxidized to $\mathrm{CO}_{2}$ rather than reduced to $\mathrm{CH}_{4}$. Since some oxidation of acetate-methyl is also happening in pure cultures of acetoclastic methanogens (Weimer and Zeikus, 1978) and an RI of around 0.2 has often been found in environments where acetate turnover was dominated by acetoclastic methanogenesis (Phelps and Zeikus, 1984; Rothfuss and Conrad, 1993; Winfrey and Zeikus, 1979), an RI value of 0.2 may in practice be used as the threshold for the change of methanogenic to oxidative acetate turnover. Based on this criterion, i.e., $\mathrm{RI}<0.2$, the lake sediments of Tapari and Verde behaved the same as for cases where acetate turnover was exclusively caused by acetoclastic methanogenesis. The percentage of acetate-dependent $\mathrm{CH}_{4}$ production was fairly consistent with the fraction of hydrogenotrophic methanogenesis, which made up the remainder of total $\mathrm{CH}_{4}$
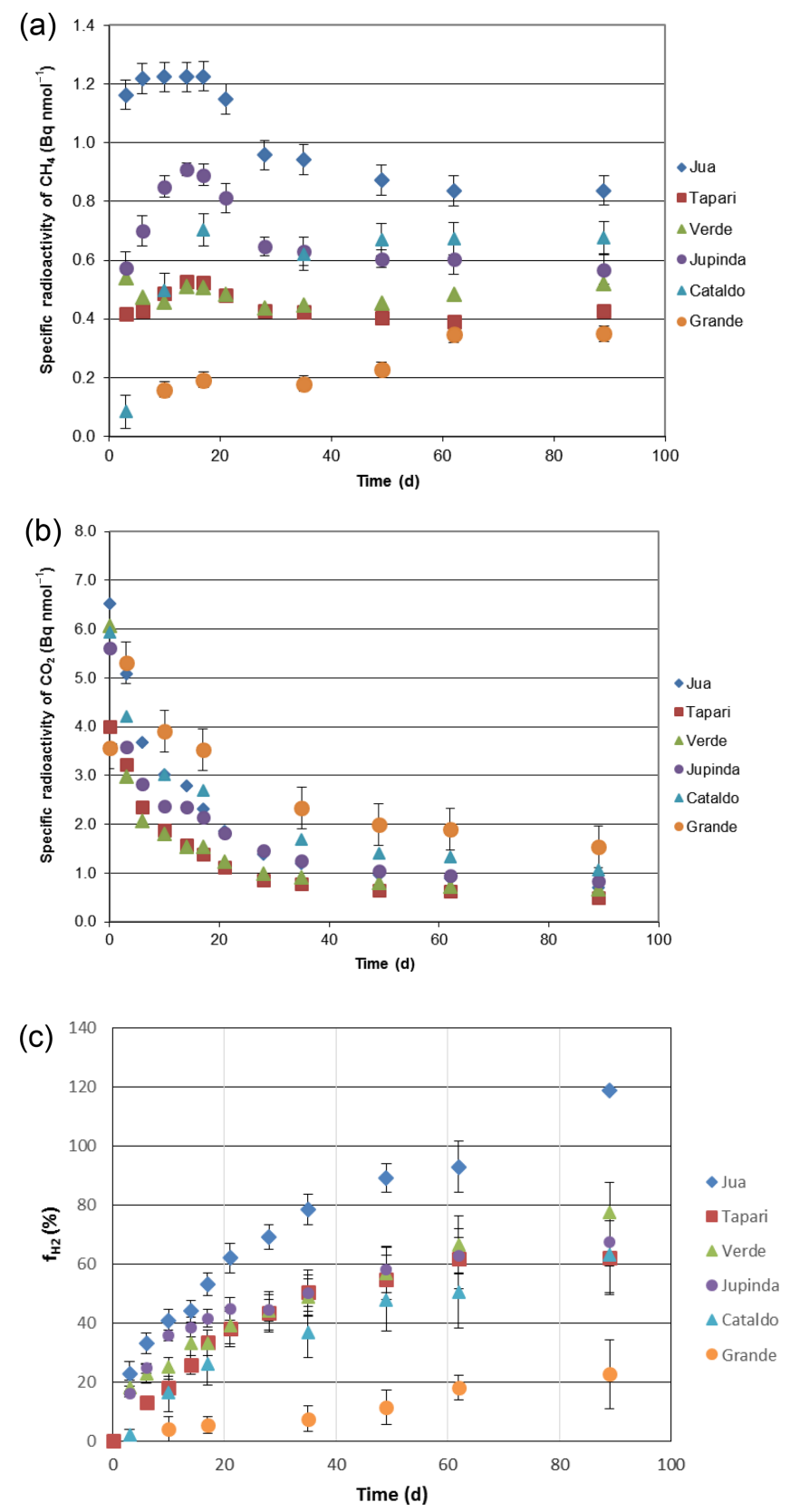

Figure 2. Conversion of radioactive bicarbonate in sediments of different Amazonian lakes: (a) specific radioactivities in $\mathrm{CH}_{4}$, (b) specific radioactivities in gaseous $\mathrm{CO}_{2}$ and (c) fractions $\left(f_{\mathrm{H}_{2}}\right)$ of hydrogenotrophic methanogenesis (mean $\pm \mathrm{SE}$ ).

production. In conclusion, the acetate turnover and $\mathrm{CH}_{4}$ production in these lake sediments behaved as expected, i.e., in a similar way to when acetoclastic methanogenesis was the sole process of acetate consumption (reaction 1 in Fig. 5).

However, the sediments of Jua and, in particular, those of Jupinda, Cataldo, and Grande exhibited RI values $>0.2$, showing that a substantial fraction of the acetate-methyl was oxidized to $\mathrm{CO}_{2}$. Hence, acetate was not exclusively con- 

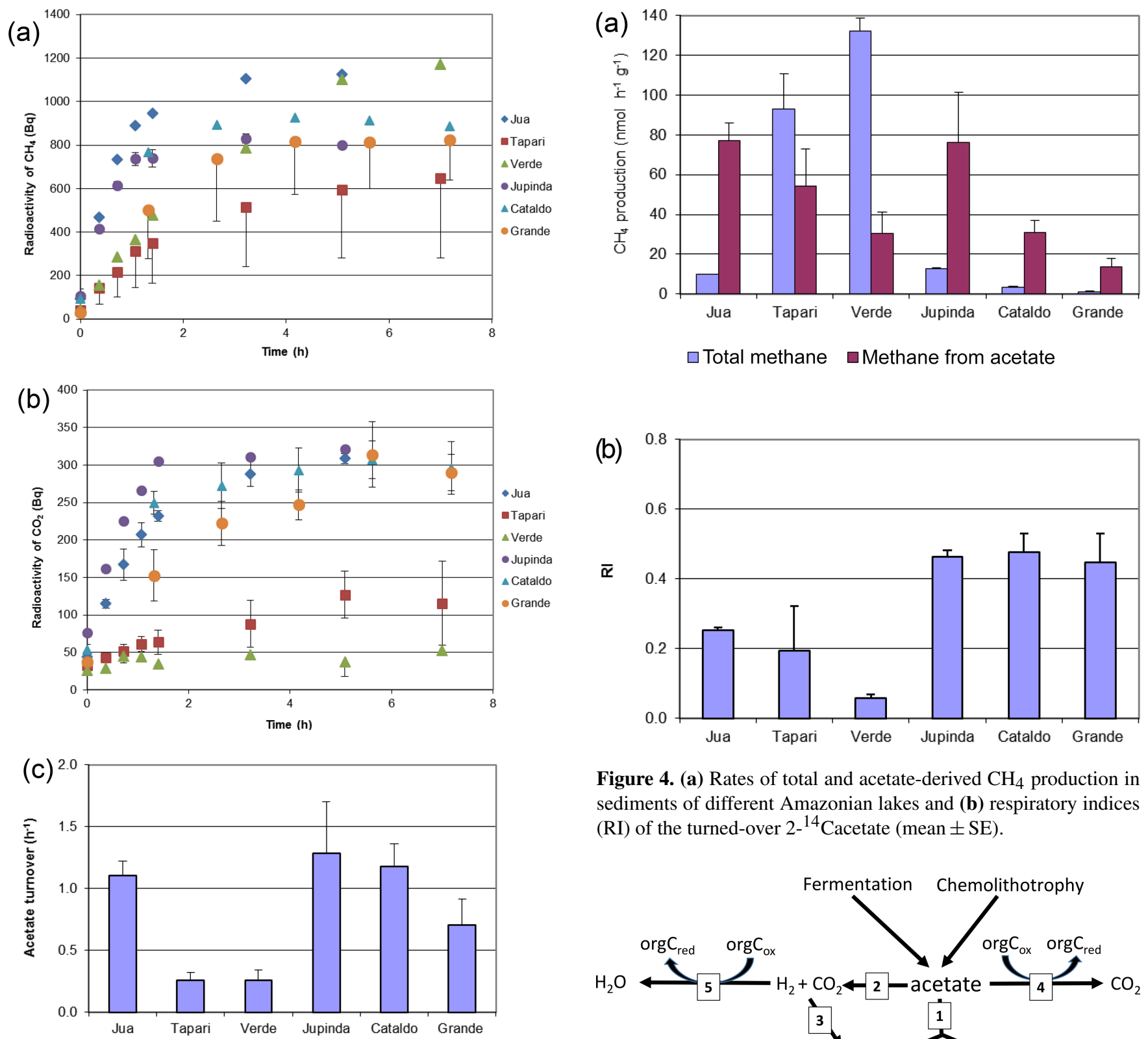

Figure 4. (a) Rates of total and acetate-derived $\mathrm{CH}_{4}$ production in sediments of different Amazonian lakes and (b) respiratory indices (RI) of the turned-over $2-{ }^{14}$ Cacetate (mean \pm SE).

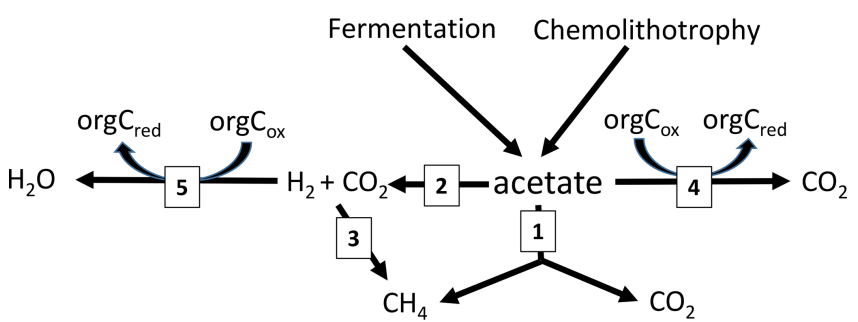

Figure 3. Conversion of $2-{ }^{14}$ Cacetate in sediments of different Amazonian lakes: (a) accumulation of radioactive $\mathrm{CH}_{4}$, (b) accumulation of radioactive gaseous $\mathrm{CO}_{2}$ and (c) acetate turnover rate constants (mean $\pm \mathrm{SE}$ ).

sumed by acetoclastic methanogenesis but was oxidized, for example, by syntrophic acetate oxidation producing $\mathrm{H}_{2}$ and $\mathrm{CO}_{2}$. Similarly, RI values $>0.2$ have been observed in the sediment of Lake Kinneret in Israel and interpreted as syntrophic acetate oxidation (Nüsslein et al., 2001). Also in the methanogenic zone of an anoxic seabed in the Baltic Sea, acetate has been shown to be degraded syntrophically (Beulig et al., 2018). The $\mathrm{H}_{2}$ and $\mathrm{CO}_{2}$ from acetate oxidation may subsequently be used as methanogenic substrates, thus supporting $\mathrm{CH}_{4}$ production (reactions 2 and 3 in Fig. 5). Such

Figure 5. Scheme of the pathways involved in acetate turnover in sediments of Amazonian lakes: (1) acetoclastic methanogenesis, (2) syntrophic acetate oxidation, (3) hydrogenotrophic methanogenesis and (4) acetate oxidation with organic electron acceptors.

support would be consistent with the relatively high fractions $\left(f_{\mathrm{H}_{2}}\right)$ of hydrogenotrophic methanogenesis observed in the sediments of lakes Jua, Jupinda, Cataldo and Grande. However, it would not explain why acetate turnover rates were higher than necessary for supporting the observed rates of total $\mathrm{CH}_{4}$ production. A possible conclusion is that acetate was converted to $\mathrm{CO}_{2}$ without concomitant production of $\mathrm{H}_{2}$. Possibly, electrons from acetate were transferred to organic electron acceptors (reaction 4 in Fig. 5), such as suggested 
in the literature (Coates et al., 1998; Lovley et al., 1996). Alternatively, acetate may have first been converted to $\mathrm{H}_{2}$ plus $\mathrm{CO}_{2}$ followed by the oxidation of $\mathrm{H}_{2}$ with organic electron acceptors (reactions 2 and 5 in Fig. 5) rather than syntrophic formation of $\mathrm{CH}_{4}$ from $\mathrm{H}_{2}$ plus $\mathrm{CO}_{2}$ (reactions 2 and 3 in Fig. 5). In conclusion, these lake sediments behaved as when acetate consumption was accomplished not only by acetatedependent methanogenesis but also by oxidative consumption.

Our conclusions are mainly based on radiotracer measurements, which may be biased. For example, acetate turnover rate constants are calculated from acetate concentrations and turnover rate constants. Acetate concentrations were only measured at the end of incubation and thus may not have been representative for the entire incubation time. Furthermore, acetate in the sediment may occur in several pools with different turnover (Christensen and Blackburn, 1982). Therefore, acetate turnover rates and acetate-dependent $\mathrm{CH}_{4}$ production rates may be overestimated if the actual acetate turnover depends on a pool size that is smaller than that analyzed. Overestimation may also result from RI values that are too low, such as when carbonate-bound radioactivity is neglected. However, such bias was avoided by acidification prior to determination of the RI. Finally, a potential bias may arise from the fact that the rates of $\mathrm{CH}_{4}$ production and the acetate turnover rates were measured in two different sets of incubation, with different incubation times. While $\mathrm{CH}_{4}$ production (and $f_{\mathrm{H}_{2}}$ ) was measured over tens of days (Fig. 2), acetate turnover was determined within $8 \mathrm{~h}$ (Fig. 3). Nevertheless, the data in the lake sediments of Tapari and Verde resulted in $\mathrm{CH}_{4}$ production and acetate turnover consistent with the operation of acetoclastic methanogenesis, which is the canonical acetate consumption pathway for methanogenic sediments. Therefore, we are confident that our results obtained from the sediments of Jua, Jupinda, Cataldo and Grande were also in a realistic range.

The determination of fractions of hydrogenotrophic methanogenesis $\left(f_{\mathrm{H}_{2}}\right)$ depends on the specific radioactivity of the dissolved $\mathrm{CO}_{2}$ pool that is involved in $\mathrm{CH}_{4}$ production. However, it is the pool of gaseous $\mathrm{CO}_{2}$ that is analyzed in the assay, assuming that its specific radioactivity is identical to that of the active dissolved pool. Since nonradioactive $\mathrm{CO}_{2}$ is permanently produced from oxidation of organic matter, there may be disequilibrium. Nevertheless, determinations of $f_{\mathrm{H}_{2}}$ using radioactive bicarbonate exhibited the same tendencies as those based on $\delta^{13} \mathrm{C}$ values and thus are probably quite reliable. Furthermore, the $f_{\mathrm{H}_{2}}$ values were fairly consistent with the fractions of acetate-dependent methanogenesis determined from the turnover of radioactive acetate.

Despite these reservations, our results collectively demonstrated that acetate turnover in tropical lake sediments did not necessarily follow a canonical pattern with acetoclastic methanogenesis as the sole or predominant process of acetate turnover, despite the fact that all these sediments contained populations of putative acetoclastic methanogenic archaea.
Acetate consumption in Methanosaeta species is known to have a relatively high affinity and a low threshold for acetate (Jetten et al., 1992). Therefore, the question arises why oxidative processes, including syntrophic acetate oxidation, could successfully compete with acetoclastic methanogenesis.

Data availability. The data are all contained in the Tables and Figures.

Author contributions. RC designed the experiments, evaluated the data and wrote the manuscript. MK did the experiments. AEP provided the samples and contributed to the discussion of the data.

Competing interests. The authors declare that they have no conflict of interest.

Financial support. This research has been supported by the Swedish Research Council Vinnova, Linköping University and the Brazilian Research Council FAPERJ.

The article processing charges for this open-access publication were covered by the Max Planck Society.

Review statement. This paper was edited by Tina Treude and reviewed by Felix Beulig and one anonymous referee.

\section{References}

Beulig, F., Roey, H., Glombitza, C., and Joergensen, B. B.: Control on rate and pathway of anaerobic organic carbon degradation in the seabed, P. Natl. Acad. Sci. USA, 115, 367-372, 2018.

Christensen, D. and Blackburn, T. H.: Turnover of ${ }^{14} \mathrm{C}$-labelled acetate in marine sediments, Mar. Biol., 71, 113-119, 1982.

Coates, J. D., Ellis, D. J., Blunt-Harris, E. L., Gaw, C. V., Roden, E. E., and Lovley, D. R.: Recovery of humic-reducing bacteria from a diversity of environments, Appl. Environ. Microbiol., 64, 1504-1509, 1998.

Conrad, R.: Contribution of hydrogen to methane production and control of hydrogen concentrations in methanogenic soils and sediments, FEMS Microbiol. Ecol., 28, 193-202, 1999.

Conrad, R., Mayer, H. P., and Wüst, M.: Temporal change of gas metabolism by hydrogen-syntrophic methanogenic bacterial associations in anoxic paddy soil, FEMS Microbiol. Ecol., 62, 265274, 1989.

Conrad, R., Klose, M., and Claus, P.: Phosphate inhibits acetotrophic methanogenesis on rice roots, Appl. Environ. Microbiol., 66, 828-831, 2000.

Conrad, R., Klose, M., and Noll, M.: Functional and structural response of the methanogenic microbial community in rice field soil to temperature change, Environ. Microbiol., 11, 1844-1853, 2009. 
Conrad, R., Claus, P., and Casper, P.: Stable isotope fractionation during the methanogenic degradation of organic matter in the sediment of an acidic bog lake, Lake Grosse Fuchskuhle, Limnol. Oceanogr., 55, 1932-1942, 2010.

Conrad, R., Noll, M., Claus, P., Klose, M., Bastos, W. R., and Enrich-Prast, A.: Stable carbon isotope discrimination and microbiology of methane formation in tropical anoxic lake sediments, Biogeosciences, 8, 795-814, https://doi.org/10.5194/bg8-795-2011, 2011.

Corbett, J., Tfaily, M. M., Burdige, D. J., Cooper, W. T., Glaser, P. H., and Chanton, J. P.: Partitioning pathways of $\mathrm{CO}_{2}$ production in peatlands with stable carbon isotopes, Biogeochemestry, 114, 327-340, 2013.

Duddleston, K. N., Kinney, M. A., Kiene, R. P., and Hines, M. E.: Anaerobic microbial biogeochemistry in a northern bog: Acetate as a dominant metabolic end product, Global Biogeochem. Cy., 16, 1063, https://doi.org/10.1029/2001GB001402, 2002.

Fu, B., Conrad, R., and Blaser, M.: Potential contribution of acetogenesis to anaerobic degradation in methanogenic rice field soils, Soil Biol. Biochem., 119, 1-10, 2018.

Gao, C., Sander, M., Agethen, S., and Knorr, K. H.: Electron accepting capacity of dissolved and particulate organic matter control $\mathrm{CO}_{2}$ and $\mathrm{CH}_{4}$ formation in peat soils, Geochim. Cosmochim. Ac., 245, 266-277, 2019.

Hädrich, A., Heuer, V. B., Herrmann, M., Hinrichs, K. U., and Küsel, K.: Origin and fate of acetate in an acidic fen, FEMS Microbiol. Ecol., 81, 339-354, 2012.

Heuer, V. B., Krüger, M., Elvert, M., and Hinrichs, K. U.: Experimental studies on the stable carbon isotope biogeochemistry of acetate in lake sediments, Org. Geochem., 41, 22-30, 2010.

Hodgkins, S. B., Tfaily, M. M., McCalley, C. K., Logan, T. A., Crill, P. M., Saleska, S. R., Rich, V. I., and Chanton, J. P.: Changes in peat chemistry associated with permafrost thaw increase greenhouse gas production, P. Natl. Acad. Sci. USA, 111, 5819-5824, 2014.

Jetten, M. S. M., Stams, A. J. M., and Zehnder, A. J. B.: Methanogenesis from acetate - A comparison of the acetate metabolism in Methanothrix soehngenii and Methanosarcina spp., FEMS Microbiol. Rev., 88, 181-197, 1992.

Ji, Y., Angel, R., Klose, M., Claus, P., Marotta, H., Pinho, L., Enrich-Prast, A., and Conrad, R.: Structure and function of methanogenic microbial communities in sediments of Amazonian lakes with different water types, Environ. Microbiol., 18, 5082-5100, 2016.

Keller, J. K., Weisenhorn, P. B., and Megonigal, J. P.: Humic acids as electron acceptors in wetland decomposition, Soil Biol. Biochem., 41, 1518-1522, 2009.

Klüpfel, L., Piepenbrock, A., Kappler, A., and Sander, M.: Humic substances as fully regenerable electron acceptors in recurrently anoxic environments, Nat. Geosci., 7, 195-200, 2014.

Lee, M. J. and Zinder, S. H.: Isolation and characterization of a thermophilic bacterium which oxidizes acetate in syntrophic association with a methanogen and which grows acetogenically on $\mathrm{H}_{2}-\mathrm{CO}_{2}$, Appl. Environ. Microbiol., 54, 124-129, 1988.

Liu, F. H. and Conrad, R.: Thermoanaerobacteriaceae oxidize acetate in methanogenic rice field soil at $50^{\circ} \mathrm{C}$, Environ. Microbiol., 12, 2341-2354, 2010.

Liu, P. F., Klose, M., and Conrad, R.: Temperature effects on structure and function of the methanogenic microbial communities in two paddy soils and one desert soil, Soil Biol. Biochem., 124, 236-244, 2018.

Liu, Y., Conrad, R., Yao, T., Gleixner, G., and Claus, P.: Change of methane production pathway with sediment depth in a lake on the Tibetan plateau, Palaeogeogr. Palaeocl., 474, 279-286, 2017.

Lokshina, L., Vavilin, V., Litti, Y., Glagolev, M., Sabrekov, A., Kotsyurbenko, O., and Kozlova, M.: Methane production in a West Siberian eutrophic fen is much higher than carbon dioxide production: incubation of peat samples, stoichiometry, stable isotope dynamics, modeling, Water Resour., 46, S110-S125, 2019.

Lovley, D. R., Coates, J. D., Blunt-Harris, E. L., Phillips, E. J. P., and Woodward, J. C.: Humic substances as electron acceptors for microbial respiration, Nature, 382, 445-448, 1996.

Müller, B., Sun, L., Westerholm, M., and Schnürer, A.: Bacterial community composition and fhs profiles of low- and high-ammonia biogas digesters reveal novel syntrophic acetate-oxidising bacteria, Biotechnol. Biofuels, 9, 48, https://doi.org/10.1186/s13068-016-0454-9, 2016.

Nüsslein, B., Chin, K. J., Eckert, W., and Conrad, R.: Evidence for anaerobic syntrophic acetate oxidation during methane production in the profundal sediment of subtropical Lake Kinneret (Israel), Environ. Microbiol., 3, 460-470, 2001.

Oren, A.: The family Methanotrichaceae, in: The Prokaryotes, edited by: Rosenberg, E., DeLong, E. F., Lory, S., Stackebrandt, E., and Thompson, F., Springer, Berlin, 298-306, 2014.

Phelps, T. J. and Zeikus, J. G.: Influence of $\mathrm{pH}$ on terminal carbon metabolism in anoxic sediments from a mildly acidic lake, Appl. Environ. Microbiol., 48, 1088-1095, 1984.

Rothfuss, F. and Conrad, R.: Vertical profiles of $\mathrm{CH}_{4}$ concentrations, dissolved substrates and processes involved in $\mathrm{CH}_{4}$ production in a flooded Italian rice field, Biogeochemestry, 18, 137$152,1993$.

Schnürer, A., Zellner, G., and Svensson, B. H.: Mesophilic syntrophic acetate oxidation during methane formation in biogas reactors, FEMS Microbiol. Ecol., 29, 249-261, 1999.

Schütz, H., Seiler, W., and Conrad, R.: Processes involved in formation and emission of methane in rice paddies, Biogeochemestry, 7, 33-53, 1989.

Vavilin, V., Rytov, S., and Conrad, R.: Modeling methane formation in sediments of tropical lakes, focusing on syntrophic acetate oxidation: dynamics and static isotope equations, Ecol. Model., 363, 81-95, 2017.

Weimer, P. J. and Zeikus, J. G.: Acetate metabolism in Methanosarcina barkeri, Arch. Microbiol., 119, 175-182, 1978.

Winfrey, M. R. and Zeikus, J. G.: Anaerobic metabolism of immediate methane precursors in Lake Mendota, Appl. Environ. Microbiol., 37, 244-253, 1979.

Yavitt, J. B. and Seidmann-Zager, M.: Methanogenic conditions in northern peat soils, Geomicrobiol. J., 23, 119-127, 2006.

Ye, R., Jin, Q., Bohannan, B., Keller, J. K., and Bridgham, S. D.: Homoacetogenesis: A potentially underappreciated carbon pathway in peatlands, Soil Biol. Biochem., 68, 385-391, 2014.

Zhang, C., Yuan, Q., and Lu, Y.: Inhibitory effects of ammonia on methanogen $m c r A$ transcripts in anaerobic digester sludge, FEMS Microbiol. Ecol., 87, 368-377, 2014.

Zinder, S. H.: Physiological ecology of methanogens, in: Methanogenesis. Ecology, Physiology, Biochemistry and Genetics, edited by: Ferry, J. G., Chapman \& Hall, New York, 128-206, 1993. 